Braz J Med Biol Res, October 2011, Volume 44(10) 1025-1035

doi: 10.1590/S0100-879X2011007500115

Moderate intensity physical training accelerates healing of full-thickness wounds in mice

F.G. Zogaib and A. Monte-Alto-Costa

The Brazilian Journal of Medical and Biological Research is partially financed by

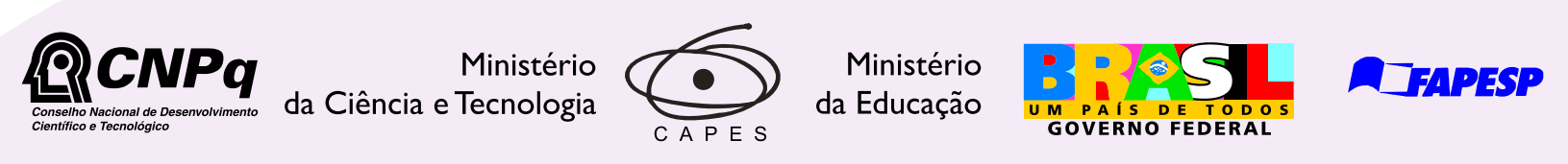

Institutional Sponsors
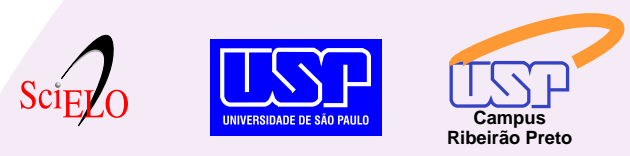

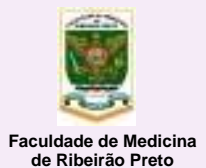

Faculdade de Medicina
de Ribeirão Preto

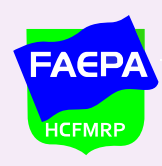

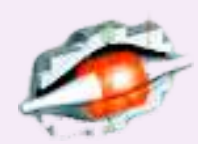

Explore High - Performance MS Orbitrap Technology In Proteomics \& Metabolomics

$\underset{\text { analitica }}{\text { analiticaweb.com.br }}$ S C I I ENTIFIC 


\title{
Moderate intensity physical training accelerates healing of full-thickness wounds in mice
}

\author{
F.G. Zogaib and A. Monte-Alto-Costa
}

Laboratório de Reparo Tecidual Cutâneo, Centro Biomédico, Universidade do Estado do Rio de Janeiro, Rio de Janeiro, RJ, Brasil

\begin{abstract}
Physical training influences the cells and mediators involved in skin wound healing. The objective of this study was to determine the changes induced by different intensities of physical training in mouse skin wound healing. Ninety male C57BL/6 mice (8 weeks old, $20-25 \mathrm{~g})$ were randomized into three physical training groups: moderate $\left(70 \% \mathrm{VO}_{2 \max }\right)$, high $\left(80 \% \mathrm{VO}_{2 \max }\right)$, and strenuous intensity $\left(90 \% \mathrm{VO}_{2 \max }\right)$. Animals trained on a motorized treadmill for 8 weeks (Elesion: physical training until the day of excisional lesion, $\mathrm{N}=10$ ) or 10 weeks ( $\mathrm{E}_{\text {euthan: }}$ physical training for 2 additional weeks after excisional lesion until euthanasia, $N=10$ ), five times/week, for $45 \mathrm{~min}$. Control groups (CG) trained on the treadmill three times/week only for $5 \mathrm{~min}(\mathrm{~N}=$ 10). In the 8th week, mice were anesthetized, submitted to a dorsal full-thickness excisional wound of $1 \mathrm{~cm}^{2}$, and sacrificed 14 days after wounding. Wound areas were measured 4,7 , and 14 days after wounding to evaluate contraction (d $\mathrm{d}_{4}, \mathrm{~d}_{7}$ and $\left.\mathrm{d}_{14}\right)$ and re-epithelialization $\left(\mathrm{d}_{14}\right)$. Fragments of lesion and adjacent skin were processed and submitted to routine histological staining. Immunohistochemistry against alpha-smooth muscle actin ( $\alpha-S M A)$ was performed. Moderate-intensity training (M) until lesion $\left(M / E_{\text {lesion }}\right)$ led to better wound closure 7 days after wounding compared to controls and $M / E_{\text {euthan }}(P<0.05)$, and both moderate-intensity groups showed better re-epithelialization rates than controls $\left(\mathrm{M} / \mathrm{E}_{\text {lesion }}=85.9 \%, \mathrm{M} / \mathrm{E}_{\mathrm{euthan}}=96.4 \%\right.$ and $M / C G=79.9 \% ; P<0.05)$. Sections of $M / E_{\text {lesion }}$ and $M / E_{\text {euthan }}$ groups stained with hematoxylin-eosin, Picrosirius red and a-SMA showed the most mature granulation tissues among all trained groups and controls. Thus, moderate-intensity physical training improves skin wound healing.
\end{abstract}

Key words: Physical training; Wound healing; Myofibroblast; Skin

\section{Introduction}

Physical training is responsible for many adaptations in connective tissue structure by its influence on collagen synthesis (1) as well as the production and secretion of growth factors (2) and inflammatory mediators (3-5). It is known that regular physical training influences the constitution of the skin. Previous studies (6) submitted young mice to daily physical training sessions of treadmill running for 22 weeks and observed that hydroxyproline concentration was higher in the skin samples of trained animals when compared to control animals. These investigators showed that the effects of physical training are not restricted to the connective tissue of the locomotor system. Another study attempted to determine the effects of a few weeks of endurance-type training on the metabolism of collagen, calcium and glycosaminoglycans in bone, muscle, tendon, and skin of young mice, and showed that collagen metabolism was accelerated by physical training in the connective tissues studied, including the skin (7).

On this basis, we may hypothesize that physical training may be able to improve the skin healing when a lesion occurs, since cutaneous wound healing is a complex physiological event designed to reestablish tissue integrity after trauma and involving a number of cells and mediators, which can be influenced by physical training.

Wound healing is usually divided into three different phases, which include inflammation, granulation tissue formation and remodeling (8). In the inflammatory phase, a clot consisting of platelets, thrombin and fibronectin is formed immediately after the injury (9). This clot releases several chemotactic substances such as vascular endothe-

Correspondence: A. Monte-Alto-Costa, Laboratório de Reparo Tecidual Cutâneo, Centro Biomédico, UERJ, Av. 28 de setembro, 87/fundos, 20551-030 Rio de Janeiro, RJ, Brasil. Fax: +55-21-2587-6511. E-mail: amacosta@uerj.br

Received February 1, 2011. Accepted August 23, 2011. Available online September 2, 2011. Published October 10, 2011. 
lial growth factor (VEGF), epithelial growth factor (EGF), platelet derived growth factor (PDGF), transforming growth factor- $\beta$ (TGF- $\beta$ ), and immunoregulatory cytokines, providing a provisional matrix that allows cell migration (10). Some investigators divide the inflammatory phase into two distinct stages: 1) early inflammation (24 to $48 \mathrm{~h}$ after wounding) characterized by the massive presence of neutrophils, and 2) later inflammation (48 to $72 \mathrm{~h}$ after wounding) characterized by the influx of monocytes and macrophages to the wound site in order to remove germs and debris (11). In the phase of granulation tissue formation, the secretion of VEGF (by keratinocytes, macrophages, fibroblasts, platelets, and endothelial cells) attracts endothelial cells that begin to form new capillary tubes (12). These new blood vessels are important for the maintenance of the granulation tissue that is being formed. Later in the phase of granulation tissue formation, platelets and macrophages send signals (PDGF and EGF) to fibroblasts in order to activate these cells to produce collagen and to proliferate (12). Recent studies have suggested that EGF is essential to the intracellular pathways, which regulate the epithelialmesenchymal transition, an important phenotype switch that must be well regulated for successful wound healing (13). Fibroblastic cells then acquire some morphological and biochemical smooth-muscle cell characteristics and differentiate into myofibroblasts, leading to wound contracture (14). When the wound reaches full re-epithelialization, the fibrotic scar produced by fibroblasts gradually degenerates within 3 to 6 months, and the scar matures and softens (15). This is the remodeling phase, which is a typical feature of the end of wound healing, and has the deposition of type I collagen in the wound as its main characteristic. In this phase, the imbalance between deposition and degradation of the extracellular matrix (ECM) components is essential for successful healing (16).

In a previous study conducted on humans (17), healthy older adults were trained to observe the role of physical training in wound healing. The participants in the study were engaged in a moderate-intensity aerobic training program including one daily hour of physical training, three times/ week, for 3 months. One month after the beginning of physical training, the participants underwent an experimental wound procedure and had their wounds measured three times/week until complete healing. Skin wound healing occurred at a faster rate in trained individuals than in the non-trained ones.

Keylock et al. (18) have assessed cutaneous wound healing and wound inflammation by training young and old mice on a motorized treadmill at a moderate intensity of $30 \mathrm{~min} /$ day for 8 days. In that study, the authors examined whether the exercise-induced alteration in wound healing in aged mice was related to a reduction in inflammatory cytokines and chemokines in the early phase of the healing process (inflammation phase). Exercise was started 3 days prior to wounding and lasted for 5 days thereafter. The results suggested that acute moderate exercise accelerates wound healing in old mice as a result of its anti-inflammatory effect on the wound.

Since different training programs have been applied in the literature $(17,18)$, the present study sought to observe whether the training-induced changes in skin wound healing were derived from acute or chronic adaptations to physical training. Thus, we decided to challenge the animals with two different training paradigms: physical training until lesion (to observe the chronic effects caused by exercise prior to wounding) or physical training until euthanasia (to observe if the acute effects of exercise would alter the wounded skin of trained subjects). We still considered it necessary to investigate the role of exercise in the whole wound healing process since the effects of training may also alter other parameters such as the phase of granulation tissue formation, whose main characteristic is collagen synthesis.

In addition, in some studies (7), animals trained at higher intensities (running twice daily, for $40 \mathrm{~min}$, at approximately $90 \% \mathrm{VO}_{2 \text { max }}$ ), while in others (18), animals trained at moderate intensities (at approximately $70 \% \mathrm{VO}_{2 \max }$ ), mimicking the amount of exercise often prescribed to promote health in the general population.

Thus, the aim of the present study was to investigate macro- and microscopic changes induced by three different intensities of physical training in skin wound healing of C57BL/6 male mice, and to evaluate wound contraction, re-epithelialization, inflammatory infiltrate, organization of collagen fibers, elastic system fiber assembly, and myofibroblastic cells.

\section{Material and Methods}

\section{Physical training}

The study was conducted following national and international protocols for the care of experimental animals and was approved by the Ethics Committee for animal use of the State University of Rio de Janeiro (CEA/194/2007). Young male C57BL/6 mice (8 weeks) weighing 20-25 g were used. Animals were housed in individual cages under a 12-h light/dark cycle, with free access to food and water and weighed once a week.

Animals were randomly divided into three groups according to physical training intensity: moderate-intensity physical training $(\mathrm{M} ; \mathrm{N}=30)$, high-intensity physical training $(\mathrm{H} ; \mathrm{N}$ $=30$ ), and strenuous physical training ( $\mathrm{S} ; \mathrm{N}=30$ ). Since some studies (7) have imposed high training intensities (approximately at $90 \% \mathrm{VO}_{2 \mathrm{max}}$ ), while others (18) have applied moderate intensities (approximately at $70 \% \mathrm{VO}_{2 \max }$ ), we chose to study three different training intensities.

After randomization by training intensity, animals were randomized again into three other groups, according to the exercise paradigm: control group (CG) untrained = animals trained only three times/week for $5 \mathrm{~min}$; trained until lesion 
$\left(E_{\text {lesion }}\right)=$ animals that trained until the day of excisional lesion (8-week training); trained until euthanasia ( $E_{\text {euthan }}$ ) $=$ animals that trained for 2 weeks more than the previous group (after excisional lesion) until the day of euthanasia (10-week training). These two different training paradigms were applied to investigate the effects of acute and chronic adaptations induced by the physical training program on skin wound healing.

In the training protocol adapted from Kohut et al. (19), mice ran on a motorized rodent treadmill five times/week for 8 weeks ( $E_{\text {lesion }}$ groups) or 10 weeks ( $E_{\text {euthan }}$ groups). Treadmill speed and physical training duration were progressively increased until achieving target duration (45 min) and target workload (based on the estimated maximum oxygen consumption - $\mathrm{VO}_{2 \max }$ - calculated for the groups): moderate-intensity (M/E $\mathrm{E}_{\text {lesion }}$ and $\left.\mathrm{M} / \mathrm{E}_{\text {euthan }}\right): 0.5 \mathrm{~km} / \mathrm{h}(70 \%$ $\left.\mathrm{VO}_{2 \mathrm{max}}\right)$; high-intensity $\left(\mathrm{H} / \mathrm{E}_{\text {lesion }}\right.$ and $\left.\mathrm{H} / \mathrm{E}_{\text {euthan }}\right): 0.7 \mathrm{~km} / \mathrm{h}$ $\left(80 \% \mathrm{VO}_{2 \max }\right)$, and strenuous-intensity $\left(\mathrm{S} / \mathrm{E}_{\text {lesion }}\right.$ and $\mathrm{S} /$ $\left.\mathrm{E}_{\text {euthan }}\right): 1.0 \mathrm{~km} / \mathrm{h}\left(90 \% \mathrm{VO}_{2 \max }\right)$. The maximum oxygen uptakes estimated for the training loads were calculated by linear regression as described elsewhere (20).

\section{Wounding procedure}

Mice were anesthetized with intraperitoneal injections of ketamine $(5 \mathrm{mg} / \mathrm{kg})$ and xylazine $(2 \mathrm{mg} / \mathrm{kg})$. The dorsal skin of the animals was shaved and a full-thickness excisional wound $\left(1 \mathrm{~cm}^{2}\right)$ was made. A transparent sheet was used to trace the edges of the lesion and to evaluate wound contraction and re-epithelialization. Excisional wounds were traced 4, 7, and 14 days after wounding. The sheet was then digitalized and analyzed using the Zeiss Image Processing System KS-400 (Zeiss-Vision, Germany) $(21,22)$. Data are reported as means \pm SD percentage of the initial wound areas.

Wound re-epithelialization was estimated by the difference between the total lesion area and the wound area still uncovered by neoepidermis. The re-epithelialized area was expressed as percentage of lesion area 14 days after wounding (23).

\section{Tissue processing and analysis}

Mice were euthanized 14 days after wounding by $\mathrm{CO}_{2}$ exposure. Portions of the wound and adjacent normal skin

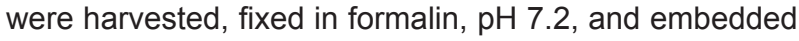
in paraffin.

Sections of paraffin-embedded wound fragments were stained with hematoxylin-eosin to observe the general organization of the tissue. Picrosirius red (PS) staining was used to identify collagen fibers. In PS-stained sections observed under polarized light, thick collagen fibers appear strongly birefringent and yellow to red in color, whereas thin collagen fibers are weakly birefringent and appear greenish in color (24). Weigert's resorcin-fucsin staining with oxidation was used to identify fibers of the elastic system in the normal skin sections.

\section{Immunohistochemistry}

Myofibroblasts expressing $\alpha$-smooth muscle actin ( $\alpha-S M A)$ were identified by immunohistochemistry. Some adaptations of the standard technique were performed to allow the use of a mouse monoclonal antibody in mouse tissue, as previously described (25). Sections were deparaffinized, hydrated, washed in phosphate-buffered saline (PBS), and incubated with the Envision system (Dako, USA) for $50 \mathrm{~min}$ to allow anti-mouse IgG to bind to tissue. Endogenous and polymer-linked peroxidase was inhibited by incubation in $3 \% \mathrm{H}_{2} \mathrm{O}_{2}$ in methanol for $30 \mathrm{~min}$. Sections were incubated with a solution of a monoclonal antibody against $\alpha-S M A$ (Dako) (1:1000) and Envision (1:20) in 1\% PBS/BSA for 2 h. Diaminobenzidine was used as chromogen and sections were counterstained with Delafield's hematoxylin. Negative controls were performed by replacing primary antibody with PBS/BSA and no labeling was observed.

\section{Statistical analysis}

Data are reported as means \pm SD. Data concerning body weight, wound contraction and re-epithelialization were analyzed by the unpaired $t$-test with Welch correction. The GraphPad Instat software (version 3.01) was used for statistical analysis (GraphPad Software Inc., USA).

\section{Results}

\section{Body weight}

There were no differences among groups (CG, E/lesion and $E$ /euthan) assigned to moderate, high and strenuous physical training intensities at the beginning of the experiments (Table 1). Both moderate-intensity and high-intensity physical training groups showed similar patterns of body weight: mice trained until lesion ( $\mathrm{M} / \mathrm{E}_{\text {lesion }}$ and $\left.\mathrm{H} / \mathrm{E}_{\text {lesion }}\right)$ presented a decreased body weight compared to control animals on $\mathrm{d}_{0}$.

No differences in body weight were found between M/ $E_{\text {lesion, }} H / E_{\text {lesion, }}$ and $S / E_{\text {lesion }}$ mice and their respective controls on $\mathrm{d}_{14}$. These animals probably gained weight because their training sessions ended when they suffered the excisional wound on $\mathrm{d}_{0}$. The $\mathrm{M} / \mathrm{E}_{\text {euthan }}, \mathrm{H} / \mathrm{E}_{\text {euthan, }}$ and $\mathrm{S} / \mathrm{E}_{\text {euthan }}$ groups presented decreased body weight when compared to their controls on $\mathrm{d}_{0}$ and $\mathrm{d}_{14}$; on $\mathrm{d}_{14}$, the animals of these three groups were lighter than $\mathrm{M} / \mathrm{E}_{\text {lesion, }} \mathrm{H} / \mathrm{E}_{\text {lesion, }}$, and $S / E_{\text {lesion }}$ mice. All physical training intensities applied in this study promoted weight loss in the animals, serving as a parameter to ensure that the animals' engagement in the training program was successful.

\section{Wound closure}

Wound closure of the $M / E_{\text {euthan }}, H / E_{\text {euthan }}$, and $S / E_{\text {euthan }}$ groups was delayed when compared to their respective controls and trained counterparts on $\mathrm{d}_{4}$ (Figures $1 \mathrm{~A}, \mathrm{~B}$, and C). The $M / E_{\text {lesion }}$ group presented a better rate of wound closure than the $M / C G$ and $M / E_{\text {euthan }}$ groups on $d_{7}$, sug- 
gesting that this result could express an effect of the animals' conditioning at a moderate-intensity physical training. No differences in wound closure were observed between the M/CG and $M / E_{\text {euthan }}$ groups on $d_{7}$, confirming that the better wound closure of the $\mathrm{M} / \mathrm{E}_{\text {lesion }}$ group could be a chronic adaptation of moderate-intensity physical training (Figure 1A).

$\mathrm{H} / \mathrm{E}_{\text {lesion }}$ and $\mathrm{H} / \mathrm{E}_{\text {euthan }}$ presented delayed wound closure when compared to $\mathrm{H} / \mathrm{CG}$ on $\mathrm{d}_{7}$ (Figure 1B). The same occurred with the $S / E_{\text {lesion }}$ and $S / E_{\text {euthan }}$ groups, which showed delayed wound closure when compared to S/CG 7 days post-wounding (Figure 1C). These findings suggest that physical training intensities of $80 \% \mathrm{VO}_{2 \max }$ or higher were responsible for delayed wound contracture on $d_{7}$. Physical training did not influence wound closure of the groups that trained at moderate, high and strenuous intensity on $\mathrm{d}_{14}$ (Figure 1A, B, and C).

\section{Re-epithelialization}

With moderate-intensity physical training, the $M / \mathrm{E}_{\text {euthan }}$ group showed the best re-epithelialization rate, followed by the $\mathrm{M} / \mathrm{E}_{\text {lesion }}$ group. Both $\mathrm{M} / \mathrm{E}_{\text {lesion }}$ and $\mathrm{M} / \mathrm{E}_{\text {euthan }}$ presented higher re-epithelialized areas than M/CG (Figure 1D). It seems that an improved neo-epidermis formation can be a chronic effect of moderate-intensity physical training that can be reinforced as the training program continues. Thus, moderate-intensity physical training affected the re-epithelialization of the $\mathrm{M} / \mathrm{E}_{\text {euthan }}$ group in a positive manner.

With high-intensity physical training, the $\mathrm{H} / \mathrm{E}_{\text {lesion }}$ group showed improved re-epithelialization when compared to $H / C G$ and $H / E_{\text {euthan }}$ (Figure $1 E$ ). With strenuous-intensity physical training, no differences in re-epithelialization were observed among groups (Figure 1F).

\section{General histology}

The control groups of the three different physical training intensities presented numerous inflammatory and fibroblastic cells distributed homogeneously in both superficial and deep regions of granulation tissue. A thick neo-epidermis could be observed in these sections (Figure 2A, D, and G). Both groups trained at moderate intensity presented less inflammatory infiltrate and a decreased number of fibroblasts compared to the control group. Numerous hair follicles and well-developed dermal papillae were observed in $\mathrm{M} / \mathrm{E}_{\text {lesion }}$ and $M / E_{\text {euthan }}$ sections (Figure $2 B$ and $C$ ).

Animals trained at high intensity presented a microscopic pattern of granulation tissue similar to that observed in groups trained at moderate intensity. Sections of the $\mathrm{H} /$ $\mathrm{E}_{\text {lesion }}$ and $\mathrm{H} / \mathrm{E}_{\text {euthan }}$ groups still showed reduced amounts of inflammatory and fibroblastic cells compared to control. A thinner neo-epidermis and numerous hair follicles and dermal papillae could be observed in both groups that trained at high intensity (Figure 2E and F).

Sections of both groups of strenuous-intensity physical training ( $S / E_{\text {lesion }}$ and $\left.S / E_{\text {euthan }}\right)$ showed a thickened neo-epidermis and a greater amount of fibroblasts. S/
Table 1. Body mass of C57BL/6 male mice $(\mathrm{N}=90)$ submitted to moderate-, high-, and strenuous-intensity physical training.

\begin{tabular}{|c|c|c|c|}
\hline & \multicolumn{3}{|c|}{ Body weight $(\mathrm{g})$} \\
\hline & Initial weight & $d_{0}$ & $d_{14}$ \\
\hline \multicolumn{4}{|c|}{ Moderate-intensity physical training $(\mathrm{N}=30)$} \\
\hline $\mathrm{M} / \mathrm{CG}$ & $20.6 \pm 1.66$ & $25.9 \pm 1.22$ & $26.3 \pm 1.0$ \\
\hline $\mathrm{M} / \mathrm{E}_{\text {lesion }}$ & $20.7 \pm 1.56$ & $24.2 \pm 1.44^{*}$ & $25.0 \pm 1.85^{\#}$ \\
\hline$M / E_{\text {euthan }}$ & $20.4 \pm 1.64$ & $23.6 \pm 1.27^{*}$ & $23.3 \pm 1.65^{\star \#}$ \\
\hline \multicolumn{4}{|c|}{ High-intensity physical training $(\mathrm{N}=30)$} \\
\hline $\mathrm{H} / \mathrm{CG}$ & $25.3 \pm 1.10$ & $27.8 \pm 1.50$ & $28.2 \pm 1.50$ \\
\hline $\mathrm{H} / \mathrm{E}_{\text {lesion }}$ & $24.9 \pm 1.39$ & $26.0 \pm 1.25^{*}$ & $27.3 \pm 1.40^{\#}$ \\
\hline $\mathrm{H} / \mathrm{E}_{\text {euthan }}$ & $25.1 \pm 1.45$ & $25.5 \pm 1.30$ & $25.3 \pm 1.65^{\star \#}$ \\
\hline \multicolumn{4}{|c|}{ Strenuous-intensity physical training $(\mathrm{N}=30)$} \\
\hline $\mathrm{S} / \mathrm{CG}$ & $23.2 \pm 1.91$ & $25.5 \pm 1.38$ & $25.8 \pm 1.44$ \\
\hline$S / E_{\text {lesion }}$ & $22.8 \pm 2.30$ & $24.5 \pm 1.40$ & $25.8 \pm 1.31^{\#}$ \\
\hline $\mathrm{S} / \mathrm{E}_{\text {euthan }}$ & $23.7 \pm 1.75$ & $23.4 \pm 1.99^{*}$ & $23.9 \pm 1.16^{\star \#}$ \\
\hline
\end{tabular}

Data are reported as means \pm SD. ${ }^{*}$ Confidence interval $(95 \% \mathrm{Cl})$ for differences between trained and control (Student $t$-test with Welch correction); ${ }^{\#} 95 \% \mathrm{Cl}$ for differences between the trained groups $\mathrm{E}_{\text {lesion }} / \mathrm{E}_{\text {euthan }}$ (Student $t$-test with Welch correction). $\mathrm{M}=$ moderate-intensity physical training; $\mathrm{H}=$ high-intensity physical training; $S=$ strenuous-intensity physical training; $C G=$ control group; $\mathrm{E}_{\text {lesion }}=$ trained until lesion; $\mathrm{E}_{\text {euthan }}=$ trained until euthanasia; $d_{0}=$ day of excisional lesion; $d_{14}=$ euthanasia.

$E_{\text {lesion }}$ sections showed a smaller amount of inflammatory cells than $S / E_{\text {euthan }}$ and $S / C G$ sections. Hair follicles and dermal papillae were almost absent in sections from animals submitted to strenuous-intensity physical training (Figure 2H and I).

\section{Organization and distribution of collagen fibers}

Collagen fibers were thin, reddish (some greenish fibers could be observed, although they were not the majority) and fragmented in the sections from control animals. Control sections showed a disorganized arrangement of collagen fibers (Figure 3A, D, and G).

Sections of the $M / E_{\text {lesion }}$ and $M / E_{\text {euthan }}$ groups showed a greater amount of collagen fibers than did M/CG and exhibited more thickened and elongated fibers than their controls. In the deep region of the granulation tissue, collagen fibers were horizontally organized, parallel to each other. In the superficial region of moderate-intensity sections, fibers were more fragmented and organized in a "basket-like" arrangement. Although some greenish fibers could be observed in the superficial region, collagen fibers in both $\mathrm{M} / \mathrm{E}_{\text {lesion }}$ and $\mathrm{M} / \mathrm{E}_{\text {euthan }}$ groups were mainly reddish, arranged homogeneously in the deep region (Figure $3 \mathrm{~B}$ and $\mathrm{C}$ ).

Sections of both high-intensity-trained groups $\left(\mathrm{H} / \mathrm{E}_{\text {lesion }}\right.$ and $H / E_{\text {euthan }}$ ) showed an increased amount of collagen fibers when compared to the sections of H/CG mice. Collagen fibers of $\mathrm{H} / \mathrm{E}_{\text {lesion }}$ and $\mathrm{H} / \mathrm{E}_{\text {euthan }}$ mice were longer and 
thicker than in control mice. High-intensity physical training sections were mainly reddish, though some greenish fibers could be observed spread in the tissue. The superficial re- gion of the granulation tissue presented disorganized fibers and the deep region presented denser fibers organized parallel to the surface (Figure 3E and F).

\section{A}

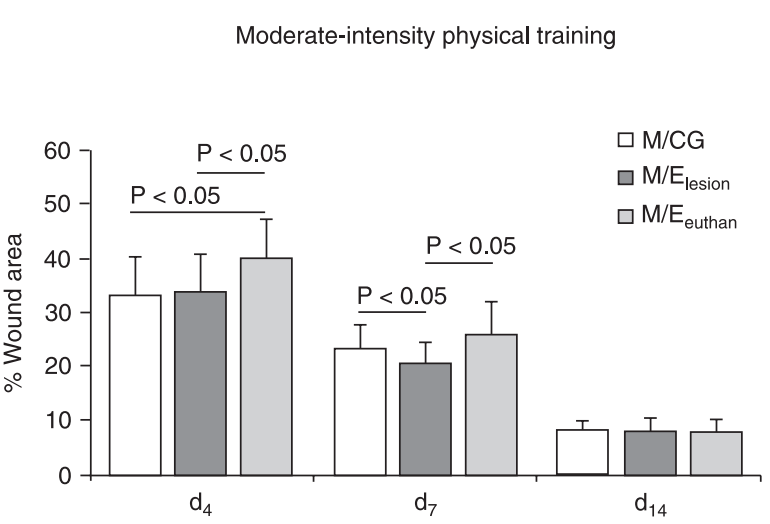

B

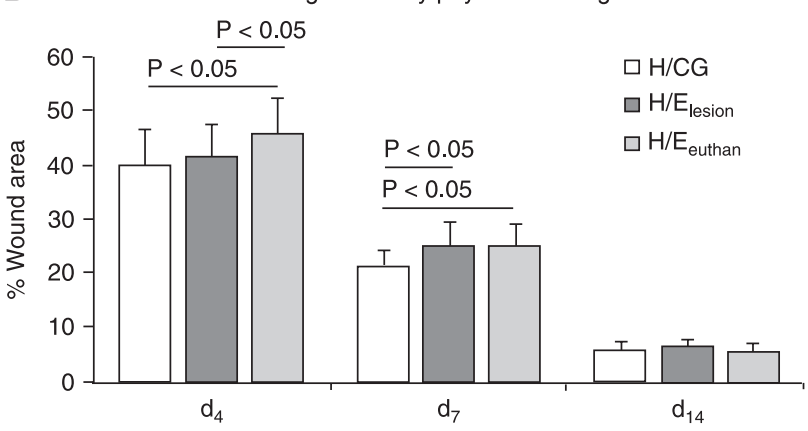

C

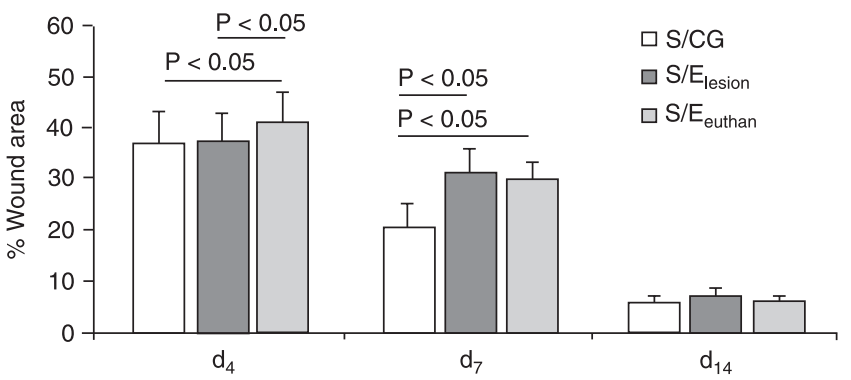

D

Re-epithelialization

Moderate-intensity physical training

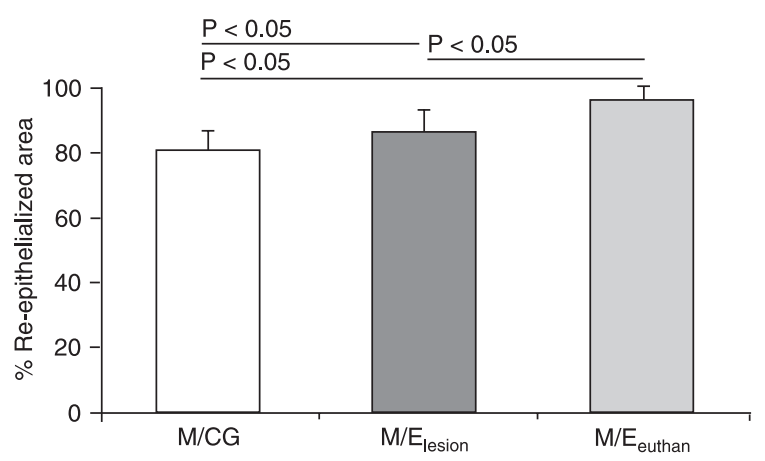

E High-intensity physical training

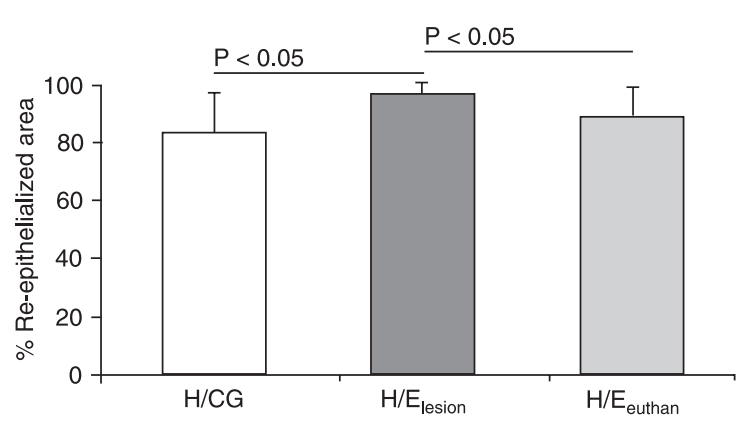

F Strenuous-intensity physical training

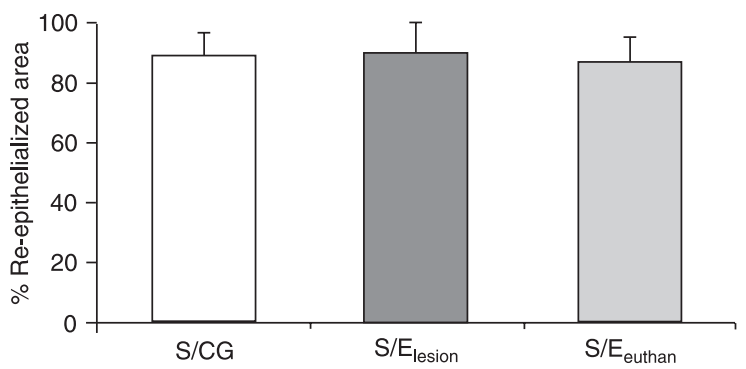

Figure 1. Effects of different physical training intensities on wound contraction 4,7 , and 14 days after wounding $(A, B, C)$ and re-epithe-

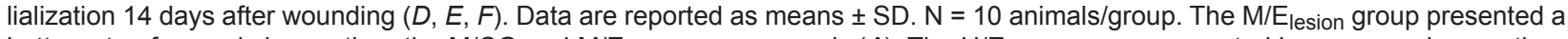
better rate of wound closure than the $M / C G$ and $M / E_{\text {euthan }}$ groups on $d_{7}(A)$. The $H / E_{\text {euthan }}$ group presented larger wound areas than the $H / C G$ and $H / E_{\text {lesion }}$ groups on $d_{4}$. Wound closure of both $H / E_{\text {lesion }}$ and $H / E_{\text {euthan }}$ groups was delayed when compared to $H / C G$ on $d_{7}(B)$. With strenuous-intensity physical training, the $S / E_{\text {euthan }}$ group presented an increased wound area when compared to $S / C G$ and $S / E_{\text {lesion }}$ on $d_{4}$. Both $S / E_{\text {lesion }}$ and $S / E_{\text {euthan }}$ groups showed delayed wound contracture when compared to $S / C G$ animals on $d_{7}$ (C). The $M / E_{\text {euthan }}$ group showed the best re-epithelialization rate, followed by $M / E_{\text {lesion }}$ group. Both $M / E_{\text {lesion }}$ and $M / E_{\text {euthan }} g r o u p s$ presented larger re-epithelialized areas than M/CG $(D)$. The $H / E_{\text {lesion }}$ group showed improved re-epithelialization when compared to $\mathrm{H} / \mathrm{CG}$ and $\mathrm{H} / \mathrm{E}_{\text {euthan }}(E)$. In the strenuous-intensity physical training, no differences were observed in re-epithelialization among groups $(F)$. Student $t$-test with Welch correction $(\mathrm{Cl}=95 \%)$. $\mathrm{M}=$ moderate-intensity physical training; $\mathrm{H}=$ high-intensity physical training; $\mathrm{S}=$ strenuous-intensity physical training; $C G=$ control group; $E_{\text {lesion }}=$ trained until lesion; $E_{\text {euthan }}=$ trained until euthanasia; $d=d a y$. 
Both strenuous-intensity-trained groups presented a dense deposition of collagen fibers. Sections of $S / E_{\text {lesion }}$ and $S / E_{\text {euthan }}$ showed reddish-colored, thickened and elongated fibers arranged roughly in parallel, either in the superficial or in the deep regions of the granulation tissue (Figure $3 \mathrm{H}$ and $\mathrm{I}$ ).

These observations suggest that animals that trained at moderate intensity presented the most organized collagen network, followed by the groups that trained at high intensity, whereas groups trained at strenuous intensity presented an increased amount of poorly organized fibers. Sections of both moderate- and high-intensity-trained groups showed more mature granulation tissues than strenuous-intensitytrained groups. Regardless of intensity, all trained groups showed a higher amount of collagen fibers than control ani- mals (Figure 3B, C, E, F, H, and I).

\section{Myofibroblast analysis}

Control sections showed a large amount of fusiform myofibroblasts parallel to the surface and spread throughout the granulation tissue (Figure 4A). Moderate-intensity-trained groups ( $M / E_{\text {lesion }}$ and $\left.M / E_{\text {euthan }}\right)$ presented some myofibroblasts arranged into the deep region of the granulation tissue (Figure 4B). In the high-intensity-trained animals $(\mathrm{H} /$ $\mathrm{E}_{\text {lesion }}$ and $\mathrm{H} / \mathrm{E}_{\text {euthan }}$ ), sections presented a pattern closely similar to that of moderate-intensity-trained groups (Figure $4 C)$. Numerous fusiform myofibroblasts could be observed all over the granulation tissue of the strenuous-intensitytrained animals $\left(S / E_{\text {lesion }}\right.$ and $S / E_{\text {euthan }}$ groups), similar to control sections (Figure 4D).

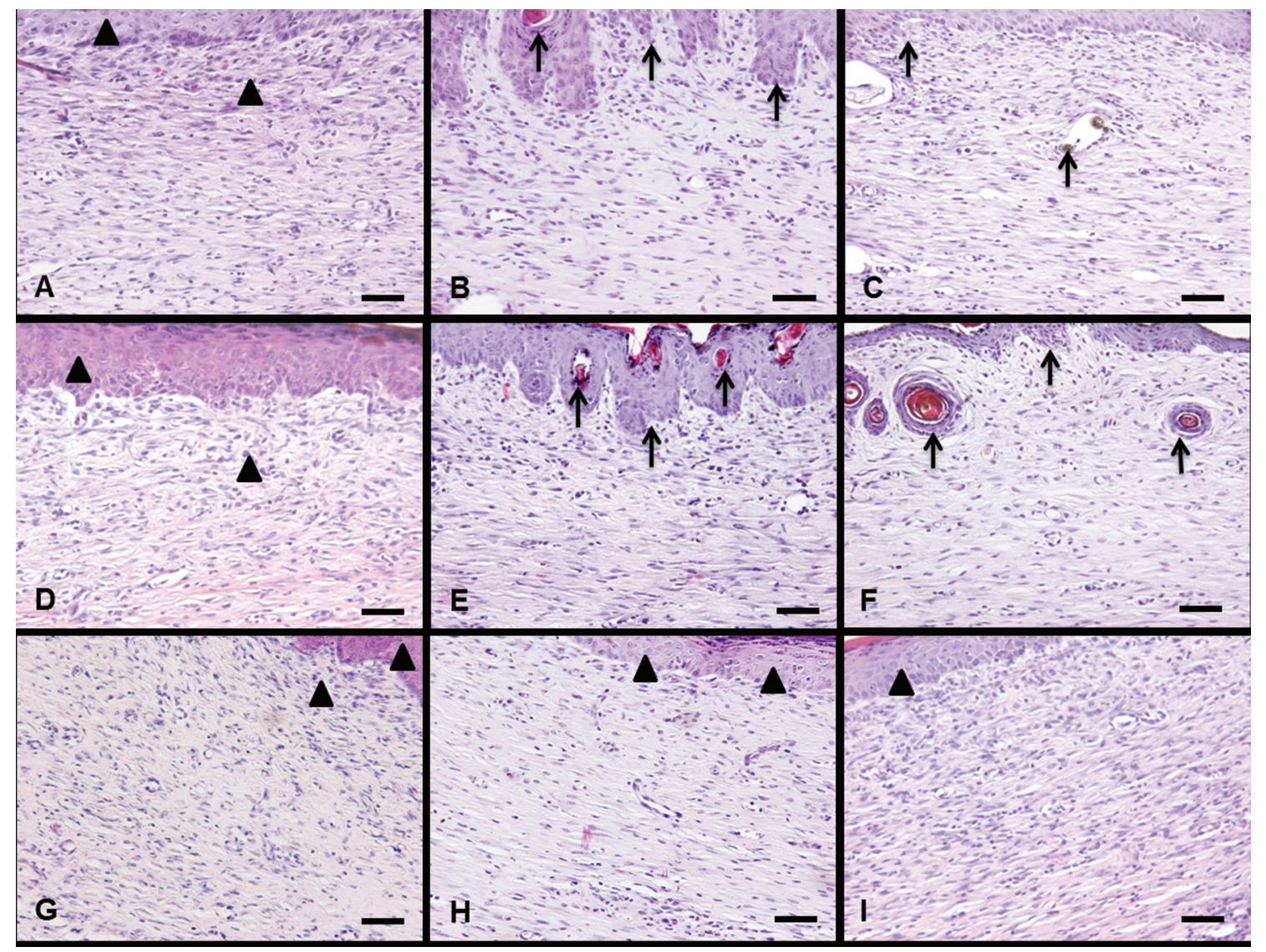

Figure 2. Effects of different physical training intensities on the formation of granulation tissue and the appearance of neo-epidermis 14 days after wounding. Sections were stained with hematoxylin-eosin. Magnification bar $=50 \mu \mathrm{m}$. Control groups showed numerous inflammatory and fibroblastic cells in the granulation tissue and a thick neo-epidermis $(A, D$, and $G$; arrowheads). $M / E_{\text {lesion, }} M / E_{\text {euthan }}, H / E_{\text {lesion, }}$, and $H / E_{\text {euthan }}$ sections presented less evidence of inflammatory infiltrate and decreased numbers of fibroblasts when compared to their respective controls, showing a similar pattern of granulation tissue. Numerous hair follicles and well-developed dermal papillae were observed in these groups $(B, C, E$, and $F$, respectively; arrows). $S / E_{\text {lesion }}$ and $S / E_{\text {euthan }}$ showed a thickened neo-epidermis (arrowheads) very similar to the control group. Hair follicles and dermal papillae were almost absent in strenuous-intensity physical training sections $(H$ and $l)$. For abbreviations, see legend to Figure 1. 


\section{Elastic system fibers}

Control sections of normal skin showed some dispersed and fragmented fibers of the elastic system. In the deep region of the control sections, some scarce thick fibers could be perceived (Figure 5A, D, and G).

In the moderate-intensity-trained animals there was a greater amount of superficial elongated fibers in the $M /$ $E_{\text {lesion }}$ and $M / E_{\text {euthan }}$ groups than in $M / C G$, even though there were no specific arrangements of these fibers in animals submitted to this physical training intensity. Some thick fibers appeared in the deep area of the tissue, as also observed in M/CG (Figure $5 \mathrm{~B}$ and $\mathrm{C}$ ).

There was an increase of fibers in the superficial region of the tissue in high-intensity-trained groups compared to $H / C G$ and to the $M / E_{\text {lesion }}$ and $M / E_{\text {euthan }}$ groups. In both groups trained at high intensity, more thick elongated fibers were observed in the transition of the intermediate to the deep regions of the skin sections (Figure 5E and F).

Remarkable changes of the elastic system were observed in the strenuous-intensity-trained groups. In the superficial region of the normal skin sections of both $\mathrm{S} /$ $E_{\text {lesion }}$ and $S / E_{\text {euthan }}$ groups, there were elongated and numerous thin fibers ("candlestick-like" arrangement). Sections of these groups showed many elongated and thickened fibers spread in both regions of the tissue (Figure $5 \mathrm{H}$ and $\mathrm{I}$ ).

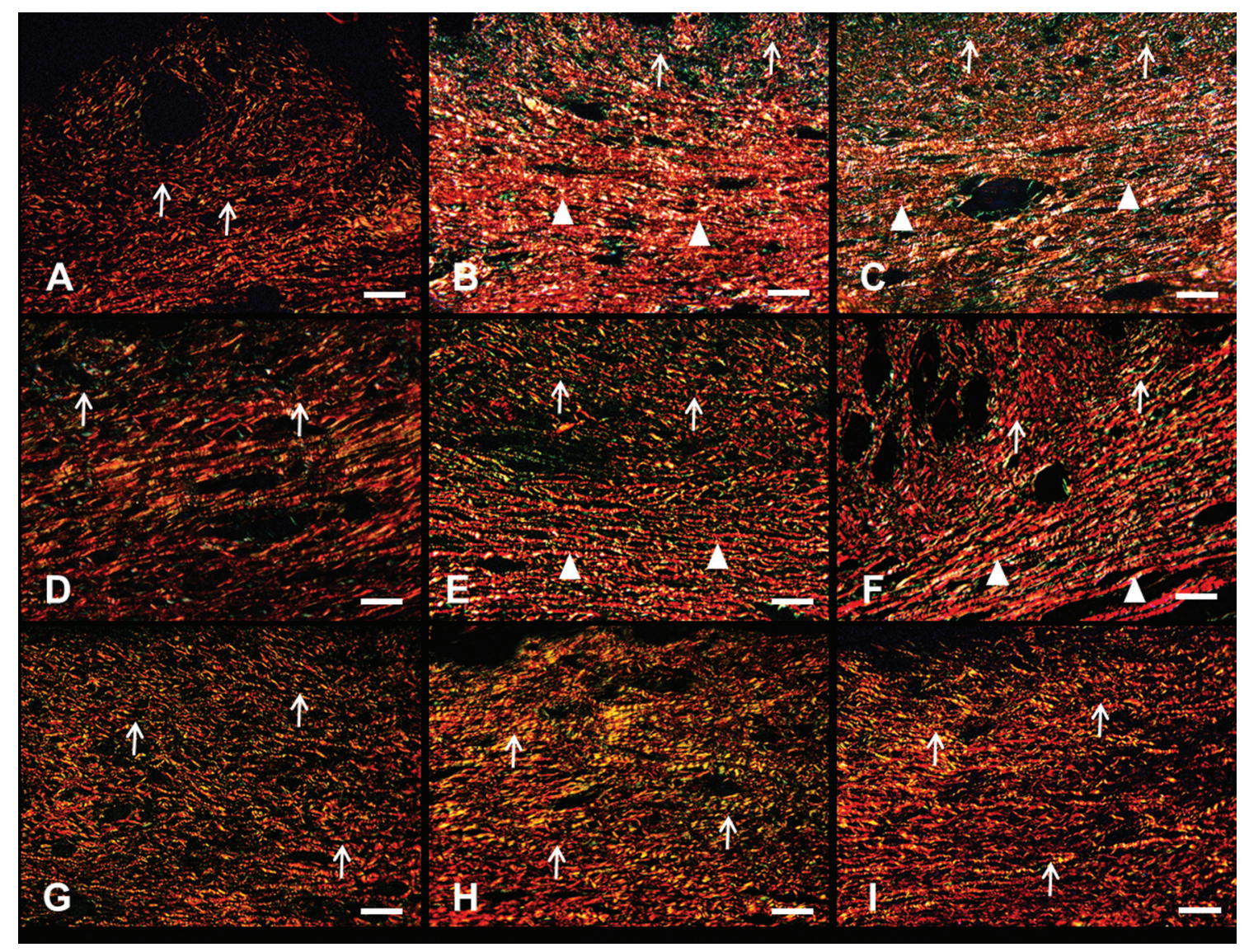

Figure 3. Effects of different physical training intensities on the organization and distribution of collagen fibers in the granulation tissue 14 days after wounding. Sections were stained with Picrosirius red. Magnification bar $=50 \mu \mathrm{m}$. Thin, reddish and fragmented collagen fibers could be observed in the granulation tissue of control groups, which showed a disorganized arrangement $\left(A, D\right.$, and $G$; arrows). Sections of the $M / E_{\text {lesion }}$ and $M / E_{\text {euthan }}$ groups exhibited collagen fibers organized in a "basket-like" arrangement in the superficial region (arrows); inside the deep region of the granulation tissue of the $\mathrm{M} / \mathrm{E}_{\text {lesion }}$ and $\mathrm{M} / \mathrm{E}_{\text {euthan }}$ groups, collagen fibers were horizontally organized and parallel to each other ( $B$ and $C$; arrowheads). Collagen fibers of the $\mathrm{H} / \mathrm{E}_{\text {lesion }}$ and $\mathrm{H} / \mathrm{E}_{\text {euthan }}$ groups were longer and thicker than in control sections. The superficial region of the granulation tissue of high-intensity-trained groups presented disorganized collagen fibers (arrows) and the deep region presented denser fibers organized parallel to each other ( $E$ and $F$; arrowheads). Strenuous-intensity-trained groups presented a dense deposition of collagen fibers; $S / E_{\text {lesion }}$ and $S / E_{\text {euthan }}$ sections showed thickened and elongated fibers arranged roughly in parallel either in the superficial or in the deep regions of the granulation tissue ( $H$ and $l$; arrows). For abbreviations, see legend to Figure 1. 


\section{Discussion}

This study is the first to describe the effects of different intensities of physical training on mouse skin wound healing. Macroscopic changes induced by physical training included a better wound closure in moderate-intensity-conditioned animals, delayed wound contraction in the high and strenuous groups on $\mathrm{d}_{7}$, and an enhanced re-epithelialization in moderate and high-intensity-trained groups. Several microscopic findings confirm macroscopic data.

Recent studies $(17,18)$ have described the influence of physical training on cutaneous wound healing. Emery et al. (17) showed that older adults who engaged for three months in a moderate-intensity aerobic activity healed their standard wounds than their sedentary controls. Those authors attributed this finding to an enhanced neuroendocrine response and suggested further evaluation of pro-inflammatory cytokines in the wound environment.

In another study (18), aged mice were trained for 30 min per day at $70 \% \mathrm{VO}_{2 \max }$ (physical training began 3 days prior to wounding and lasted 5 days thereafter); trained aged animals presented smaller wound areas than their untrained aged controls. The authors (18) observed effects of physical training in the early phases of wound healing (up to 6 days after wounding) and showed that moderateintensity exercise reduced TNF- $\alpha, \mathrm{KC}$, and MCP-1 levels and all inflammatory cytokines that were elevated in wounds of aged mice. These results may be observed in a physical training program of greater duration, since moderate physical conditioning is known to reduce the anti-inflammatory response as a chronic adaptation to training (26).

In the present study, better wound closure was observed in animals trained at moderate intensity seven days after wounding, in agreement with previous reports $(17,18)$, although these studies did not analyze wound closure and re-epithelialization separately. Thus, it is difficult to know if these investigators $(17,18)$ observed a smaller wound area because of a higher rate of wound closure or because

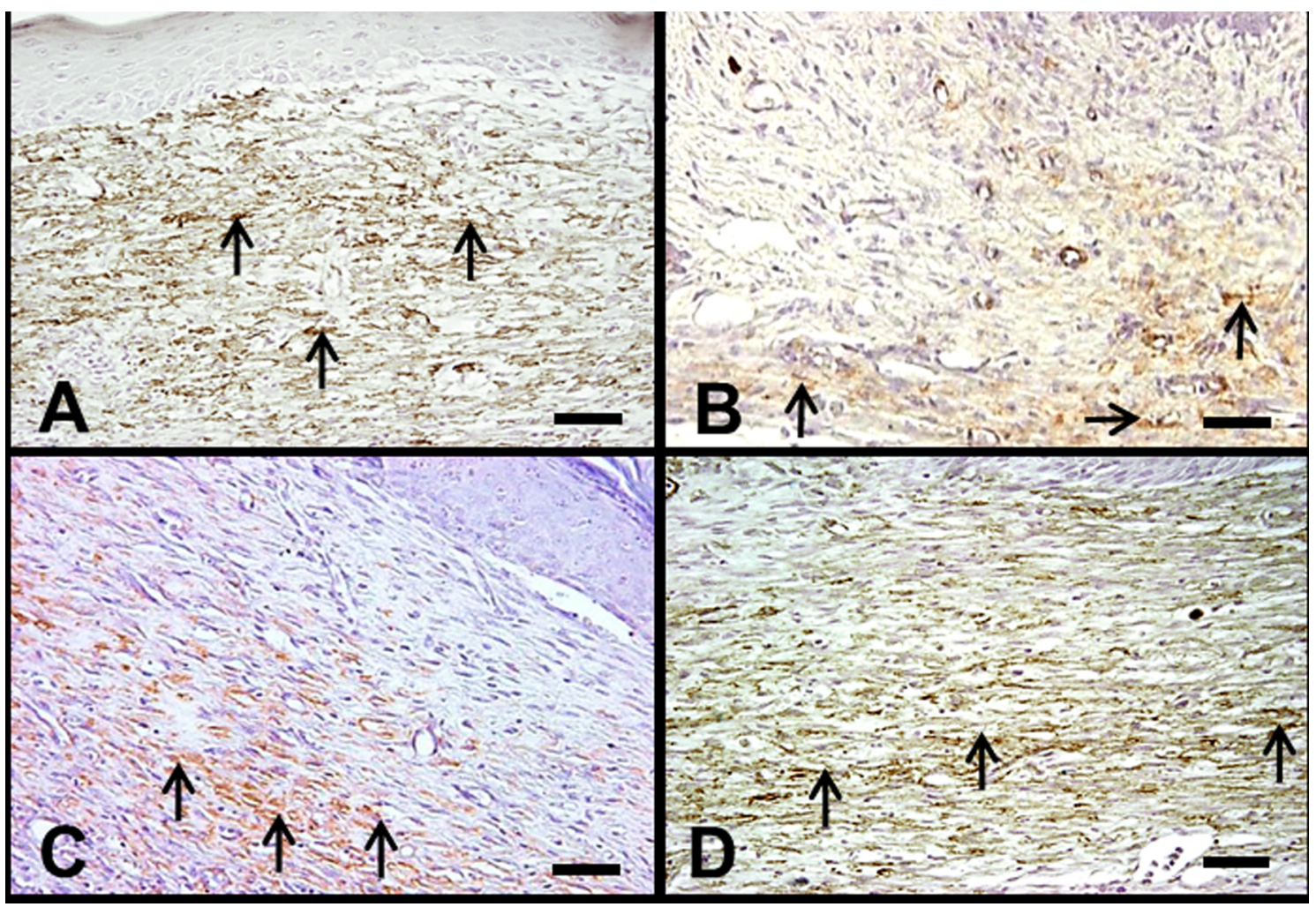

Figure 4. Effects of different physical training intensities on the distribution of myofibroblasts in the granulation tissue 14 days after wounding. Myofibroblasts expressing $\alpha$-SMA were localized by immunohistochemistry. Magnification bar $=50$ $\mu \mathrm{m}$. Control sections showed a large amount of fusiform myofibroblasts spread throughout the granulation tissue $(A$; arrows). Moderate-intensity-trained groups ( $M / \mathrm{E}_{\text {lesion }}$ and $\left.\mathrm{M} / \mathrm{E}_{\text {euthan }}\right)$ presented some myofibroblasts arranged inside the deep region of the granulation tissue ( $B$; arrows). In the high-intensity-trained animals $\left(H / E_{\text {lesion }}\right.$ and $\left.H / E_{\text {euthan }}\right)$, sections presented a pattern closely similar to that of moderate-intensity-trained groups ( $C$; arrows). Numerous fusiform myofibroblasts could be observed all over the granulation tissue of the strenuous-intensity-trained animals (S/E $\mathrm{E}_{\text {lesion }}$ and $\mathrm{S} / \mathrm{E}_{\text {euthan }}$ groups), similar to control sections ( $D$; arrows). For abbreviations, see legend to Figure 1. 
of a larger re-epithelialized area. Our data also showed enhanced re-epithelialization of both moderate-intensitytrained groups and the high-intensity group that trained for 14 days after wounding. We suggest that physical conditioning prior to wounding has positive effects on both moderate- and high-intensity-trained animals.

Cytokines systemically released during physical training could influence the wounds locally. It is possible that the anti-inflammatory cytokine balance experienced by the animals trained at moderate intensity (27) would be able to reduce the amount of inflammatory cells in the granulation tissue. In fact, animals that trained at $80 \% \mathrm{VO}_{2 \max }\left(\mathrm{H} / \mathrm{E}_{\text {lesion }}\right.$ and $\mathrm{H} / \mathrm{E}_{\text {euthan }}$ ) also presented a reduction of the inflamma- tory infiltrate in the granulation tissue. On the other hand, strenuous physical training may induce inflammatory reactions and immune disturbances because of the increased concentrations of pro-inflammatory mediators (27).

According to Gokhale et al. (28), strenuous-physical activity increased serum TNF- $\alpha$ and IL- 6 levels. This might have caused an increase in the amount of inflammatory cells in the strenuous-physical training group that trained until euthanasia. Possibly, the reduction of the inflammatory condition in the $\mathrm{S} / \mathrm{E}_{\text {lesion }}$ group was due to the cessation of the pro-inflammatory stimuli in the strenuous-intensity physical training because of the conclusion of the training program.

Physical training is also responsible for the increased

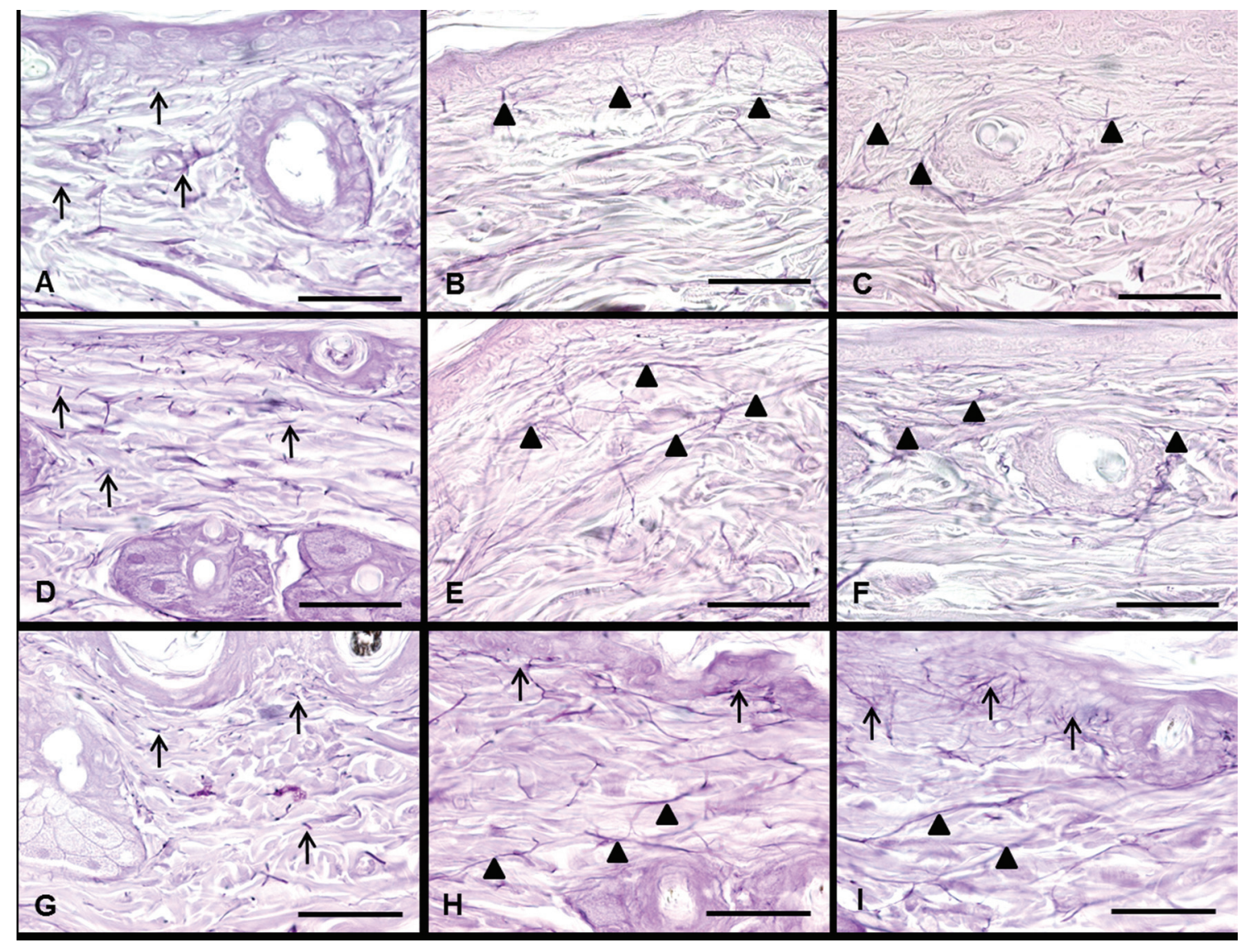

Figure 5. Effects of different physical training intensities on the elastic system assembly of normal skin sections. Sections were stained with resorcin fucsin Weigert with previous oxidation. Magnification bar $=50 \mu \mathrm{m}$. Control sections of normal skin showed some dispersed and fragmented fibers of the elastic system ( $A, D$, and $G$; arrows). Weigert's normal skin sections showed an increased amount of thin fibers of the elastic system without any specific arrangement in the superficial area of the tissue of the $M / E_{\text {lesion }}$ and $M / E_{\text {euthan }}$ groups ( $B$ and $C$; arrowheads). $H / E_{\text {lesion }}$ and $H / E_{\text {euthan }}$ groups presented the same pattern of thin and elongated fibers in the superficial region, but showed larger amounts of these fibers than moderate-intensity-trained groups. The $\mathrm{H} / \mathrm{E}_{\text {lesion }}$ and $\mathrm{H} / \mathrm{E}_{\text {euthan }}$ groups also showed more elongated fibers in the transition from the intermediate to the deep regions of the skin sections ( $E$ and $F$; arrowheads). The $S / E_{\text {lesion }}$ and $S / E_{\text {euthan }}$ groups showed elongated and numerous thin fibers organized in a "candlestick-like" arrangement in the superficial region of the normal skin sections of these groups (arrows). In the intermediate and deep regions of these sections, many elongated and thickened fibers were present ( $H$ and $l$; arrowheads). For abbreviations, see legend to Figure 1. 
collagen turnover in connective tissue structures such as tendons, ligaments, bone, and muscle (2). Physical training results in an increased turnover of collagen type $I$ in the local connective tissue of the peritendinous region (29). The skin might not be different from all other components of connective tissue when subjects are submitted to physical training. The present data agree with the findings of other studies $(6,7)$, which demonstrated that the amount of collagen is increased in the skin of trained mice. In the present study, all trained groups, regardless of intensity, presented a higher quantity of collagen fibers; the feature that suffered change was the arrangement of these fibers. $M / E_{\text {lesion }}$ and $\mathrm{M} / \mathrm{E}_{\text {euthan }}$ showed the best arrangement of collagen fibers, followed by $\mathrm{H} / \mathrm{E}_{\text {lesion }}$ and $\mathrm{H} / \mathrm{E}_{\text {euthan }}$.

Finally, the present study was the first to describe the microscopic characteristics of the elastic system fibers in the normal skin of trained young mice submitted to different physical training intensities. Strenuous physical training induced a higher amount and better arrangement of thin and thick fibers of the elastic system in the normal skin of trained mice. These findings suggest that, although some

\section{References}

1. Koskinen SO, Heinemeier $\mathrm{KM}$, Olesen JL, Langberg $\mathrm{H}$, Kjaer M. Physical exercise can influence local levels of matrix metalloproteinases and their inhibitors in tendon-related connective tissue. J Appl Physiol 2004; 96: 861-864.

2. Kjaer M. Role of extracellular matrix in adaptation of tendon and skeletal muscle to mechanical loading. Physiol Rev 2004; 84: 649-698.

3. Jonsdottir IH, Schjerling P, Ostrowski K, Asp S, Richter EA, Pedersen BK. Muscle contractions induce interleukin-6 mRNA production in rat skeletal muscles. J Physiol 2000; 528 (Part 1): 157-163.

4. Petersen AM, Pedersen BK. The anti-inflammatory effect of exercise. J Appl Physiol 2005; 98: 1154-1162.

5. Woods JA. Physical activity, exercise, and immune function. Brain Behav Immun 2005; 19: 369-370.

6. Kiiskinen A, Heikkinen E. Physical training and connective tissues in young mice. Biochemistry of skin. Br J Dermatol 1976; 95: 525-529.

7. Suominen H, Kiiskinen A, Heikkinen E. Effects of physical training on metabolism of connective tissues in young mice. Acta Physiol Scand 1980; 108: 17-22.

8. Singer AJ, Clark RA. Cutaneous wound healing. N Engl J Med 1999; 341: 738-746.

9. Broughton G, Janis JE, Attinger CE. Wound healing: an overview. Plast Reconstr Surg 2006; 117: 1e-32e.

10. Amadeu TP, Coulomb B, Desmouliere A, Costa AM. Cutaneous wound healing: myofibroblastic differentiation and in vitro models. Int J Low Extrem Wounds 2003; 2: 60-68.

11. Korting HC, Schollmann C, White RJ. Management of minor acute cutaneous wounds: importance of wound healing in a moist environment. J Eur Acad Dermatol Venereol 2011; 25: 130-137.

12. Broughton G, Janis JE, Attinger CE. The basic science of improvement could be observed in the elastic system of moderate- and high-intensity-trained animals, strenuousintensity physical training was the one that better promoted the appearance and arrangement of elastic system fibers in the normal skin of mice.

According to the present data, we conclude that moderate-intensity physical training promotes better wound closure and enhances re-epithelialization, and that strenuous physical training promotes elastogenesis in the unwounded skin of trained mice. Thus, moderate-intensity training could be employed as a medical care strategy for patients with chronic wounds and should be considered in the prophylactic management of diabetic patients.

\section{Acknowledgments}

We thank Thaís Porto Amadeu, Tatiana Almeida Pádua and Janaina de Lima Georgii from the Tissue Repair Laboratory for technical help. Research supported by grants from CNPq and FAPERJ to A. Monte-Alto-Costa. wound healing. Plast Reconstr Surg 2006; 117: 12S-34S.

13. Nakamura M, Tokura $Y$. Epithelial-mesenchymal transition in the skin. J Dermatol Sci 2011; 61: 7-13.

14. Darby I, Skalli O, Gabbiani G. Alpha-smooth muscle actin is transiently expressed by myofibroblasts during experimental wound healing. Lab Invest 1990; 63: 21-29.

15. Kanazawa Y, Nomura J, Yoshimoto S, Suzuki T, Kita K, Suzuki N, et al. Cyclical cell stretching of skin-derived fibroblasts downregulates connective tissue growth factor (CTGF) production. Connect Tissue Res 2009; 50: 323329.

16. Costa AM, Peyrol S, Porto LC, Comparin JP, Foyatier JL, Desmouliere A. Mechanical forces induce scar remodeling. Study in non-pressure-treated versus pressure-treated hypertrophic scars. Am J Pathol 1999; 155: 1671-1679.

17. Emery CF, Kiecolt-Glaser JK, Glaser R, Malarkey WB, Frid DJ. Exercise accelerates wound healing among healthy older adults: a preliminary investigation. J Gerontol A Biol Sci Med Sci 2005; 60: 1432-1436.

18. Keylock KT, Vieira VJ, Wallig MA, DiPietro LA, Schrementi $M$, Woods JA. Exercise accelerates cutaneous wound healing and decreases wound inflammation in aged mice. $A m \mathrm{~J}$ Physiol Regul Integr Comp Physiol 2008; 294: R179-R184.

19. Kohut ML, Thompson JR, Lee W, Cunnick JE. Exercise training-induced adaptations of immune response are mediated by beta-adrenergic receptors in aged but not young mice. J Appl Physiol 2004; 96: 1312-1322.

20. Schefer V, Talan MI. Oxygen consumption in adult and AGED C57BL/6J mice during acute treadmill exercise of different intensity. Exp Gerontol 1996; 31: 387-392.

21. Amadeu TP, Costa AM. Nitric oxide synthesis inhibition alters rat cutaneous wound healing. J Cutan Pathol 2006; 33: 465473. 
22. Souza BR, Santos JS, Costa AM. Blockade of beta1- and beta2-adrenoceptors delays wound contraction and reepithelialization in rats. Clin Exp Pharmacol Physiol 2006; 33: $421-430$

23. Amadeu TP, Seabra AB, de Oliveira MG, Costa AM. Snitrosoglutathione-containing hydrogel accelerates rat cutaneous wound repair. J Eur Acad Dermatol Venereol 2007; 21: 629-637.

24. Junqueira LC, Bignolas G, Brentani RR. Picrosirius staining plus polarization microscopy, a specific method for collagen detection in tissue sections. Histochem $J$ 1979; 11: 447455.

25. Cardoso JF, Souza BR, Amadeu TP, Valenca SS, Porto LC, Costa AM. Effects of cigarette smoke in mice wound healing is strain dependent. Toxicol Pathol 2007; 35: 890-896.
26. Mathur N, Pedersen BK. Exercise as a mean to control low-grade systemic inflammation. Mediators Inflamm 2008; 2008: 109502.

27. Tuan TC, Hsu TG, Fong MC, Hsu CF, Tsai KK, Lee CY, et al. Deleterious effects of short-term, high-intensity exercise on immune function: evidence from leucocyte mitochondrial alterations and apoptosis. Br J Sports Med 2008; 42: 1115.

28. Gokhale R, Chandrashekara S, Vasanthakumar KC. Cytokine response to strenuous exercise in athletes and non-athletes - an adaptive response. Cytokine 2007; 40: 123-127.

29. Langberg H, Rosendal L, Kjaer M. Training-induced changes in peritendinous type I collagen turnover determined by microdialysis in humans. J Physiol 2001; 534: 297-302. 